\title{
Agroforestry and reforestation with the Gold Standard-Decision Analysis of a voluntary carbon offset label
}

\author{
Leonie Netter $^{1}$ (D) Eike Luedeling ${ }^{1} \cdot$ Cory Whitney $^{1}$
}

Received: 26 December 2020 / Accepted: 22 December 2021 / Published online: 1 February 2022

(C) The Author(s) 2022

\begin{abstract}
Voluntary standards can help to ensure the quality of projects eligible for carbon offsetting, i.e., selling carbon certificates. However, in deciding on whether to adopt such standards, the managers of carbon offset projects are faced with uncertainty regarding the costs and risks involved. Decision Analysis provides a helpful set of tools that can support such decisions by forecasting outcomes under different scenarios. We applied Decision Analysis methods to generate models for the decisions to certify two projects in Costa Rica with the voluntary carbon offset label "The Gold Standard". We evaluated certifying an additional site of a partially certified reforestation project, as well as the initial certification of an agroforestry project.

We calibrated and interviewed decision-makers and stakeholders of the certification projects to identify important parameters and translate these into a decision model. We ran the final decision model as a Monte Carlo simulation to project plausible ranges of decision outcomes, expressed as Net Present Values and annual cash flows. We identified critical uncertainties and research priorities by using the Expected Value of Perfect Information. The results indicate that certification of the two projects would result in a positive Net Present Value. The partially low return on investment of the certification, however, shows the need for projects to undergo thorough evaluation and generate customized strategies before participating in a voluntary carbon offset scheme. The Decision Analysis approaches we describe can help to improve the process of decision making under uncertainty and should be widely adopted for evaluating the potential impacts of certification.
\end{abstract}

Keywords Decision Analysis · Monte Carlo simulation · Reforestation · Agroforestry · Carbon credits $\cdot$ Gold Standard

\section{Introduction}

Forests absorb the equivalent of roughly $2 \mathrm{G}$, of $\mathrm{CO}_{2}$ each year (FAO 2018). At the same time, forest loss and degradation are estimated to contribute approximately $20 \%$ of annual greenhouse gas emissions globally. Although deforestation carbon fluxes decreased by

Leonie Netter

leonie.netter@posteo.net

1 University of Bonn, INRES Horticultural Sciences, Auf dem Hügel 6, 53121 Bonn, Germany 
about one-third from 1990 to 2020, deforestation is still the second largest anthropogenic source of atmospheric $\mathrm{CO}_{2}$ (after fossil fuel combustion) (FAO 2018, 2020; van der Werf et al. 2009). As a strategy to mitigate climate change, the Kyoto Protocol's Clean Development Mechanism (CDM) offers an economic reward for projects that sequester $\mathrm{CO}_{2}$ or reduce emissions of other greenhouse gases (GHG). Emission reductions achieved, e.g., through afforestation and reforestation (A/R) activities, can be sold in the form of carbon certificates, and due to their high $\mathrm{CO}_{2}$ fixation potential, forests are an important sector of the global carbon credit market (Bumpus and Liverman 2008; UNFCCC 1997). The socalled carbon offsets allow developed economies to meet their emission reduction targets by purchasing carbon credits that are associated with projects in developing economies (UNFCCC 2007). Parallel to the CDM, a Voluntary Carbon Offset Market (VCM) with private actors has emerged, where carbon credits are sold in the form of Verified Emission Reductions (VER), with each VER corresponding to $1 \mathrm{t}$ of $\mathrm{CO}_{2}$ equivalent (Bumpus and Liverman 2008). Critics have pointed out that the CDM market has many shortcomings (such as too much bureaucracy and a lack of sustainable development co-benefits), which the VCM aimed to address. However, the VCM has also faced criticism, such as missing transparency and double-counting of offsets. As a response to the criticism, voluntary carbon offset standards were created in order to standardize the quality of projects eligible for carbon offsetting (Lovell 2010). One of the most important carbon offset labels, especially in the forestry and land use sector, is the Gold Standard. It was initiated in 2006 by the World Wide Fund for Nature (WWF) and offers several methodologies under which projects can be certified, including an "A/R GHG Emissions Reduction \& Sequestration Methodology" (The Gold Standard 2017).

When deciding on investments in certification, e.g., with the Gold Standard, project managers are faced with uncertainty. Studies have shown that strong carbon offset certifications like the Gold Standard can increase consumers' willingness-to-pay for carbon credits and for the co-benefits associated with the certification (Liu et al. 2015; MacKerron et al. 2009). On the other hand, establishing and maintaining the certification of a project often comes with high costs and risks, and little research is available on the overall benefits of certification (Galik and Jackson 2009). The decision on whether or not to apply for certification, e.g., with the Gold Standard, is therefore influenced by many factors, including the time and effort required to prepare and maintain the certification, the certification fee, the potential additional income, or the change in consumer's perception of the project. Some of these variables are hard to quantify, making the decision about potential certification complex and difficult.

The need to take practical decisions within complex ecological and economic systems is a challenge many decision-makers face. This is particularly the case with silvicultural and agricultural systems, which are characterized by uncertainty and dynamically changing and interacting factors. Decision Analysis approaches allow researchers to capture the state of knowledge on all processes and input variables, e.g., from local knowledge holders (experts, stakeholders, and decision-makers) in the form of probability distributions. The input parameters are translated into probabilistic simulations that predict the full range of plausible outcomes, improving the process of decision-making under uncertainty (Lanzanova et al. 2019; Luedeling and Shepherd 2016).

In the field of forestry, Uncertainty Analysis and Multi-Criteria Decision Analysis have been used for a range of applications. Kangas and Kangas (2004) provided a useful theoretical overview with practical examples, e.g., on the management of forests and forest ecosystems (Fürstenau et al. 2007; Rauscher et al. 2000), a topic that is also covered by Kumar et al. (2021). While most studies aim to reflect the preferences of 
stakeholders, experts and decision-makers, they rarely include expert knowledge elicitation for missing data. Instead, models are often simplified by excluding relevant factors or by using fixed values, even for variables that are clearly not precisely known. The values assumed in such studies may not be reasonable representations of reality. Such simplified models often make major assumptions e.g., about advanced agricultural management practices, or leave out important uncertainties related to social behavior and economic environments (Shepherd et al. 2015). Research approaches are available that allow studies to work with ranges and probabilities where data is uncertain or missing, using Monte Carlo simulations, where a large number of scenarios are virtually generated based on probability distributions for all input variables to obtain a range of potential outcomes (Hubbard 2014). Davis and Keller (1997) used Monte Carlo simulations for slope stability prediction in forests. Lähtinen et al. (2008) applied Multi-Criteria Decision Analysis to analyze the relative importance of tangible and intangible resources in the forestry industry. Entezari et al. (2020) combined Monte Carlo algorithms with spatial data to facilitate forest inventories.

There is considerable scope for Decision Analysis methods to be applied in forestry and agricultural management. Luedeling and Shepherd (2016) argue that Decision Analysis can solve the problem of data gaps and allow explicit consideration of risks and variability in agriculture. Monte Carlo-based decision models (Favretto et al. 2017; Rosenstock et al. 2014) as well as Bayesian network models (Whitney et al. 2018) can help provide robust guidance for decision-making without cost-intensive long-term data collection. In the field of agriculture, Decision Analysis approaches have been used for many applications, e.g., to assess investment options in honey value chains (Wafula et al. 2018), the nutritional value of home gardens (Whitney et al. 2017), intervention options to prevent reservoir sedimentation (Lanzanova et al. 2019), or the viability of agroforestry investments (Do et al. 2020).

Carbon offsetting has been analyzed from many different angles, including governance (Bumpus and Liverman 2008), auditing effectiveness of voluntary standards (Foster et al. 2017), impact on livelihoods (Herr et al. 2019), and climate change mitigation (van der Gaast et al. 2018). Only few studies assess voluntary carbon offset standards from the point of view of the projects that provide carbon credits (Herr et al. 2019; Lansing 2015; Lehmann 2019). Several authors have recommended evaluating the individual prerequisites of carbon offsetting projects before taking a decision, and some provide guidelines on generally identifying the potential social, economic, and environmental benefits for projects (ICROA 2014; Kollmuss et al. 2008). However, none of these studies quantified the potential benefits a priori. The risks and benefits involved in investing in carbon offsetting certifications therefore often remain unclear. In this paper, we demonstrate the use of Decision Analysis in the context of voluntary carbon offsetting labels. We used an innovative Decision Analysis approach to evaluate the prospective benefits of voluntary carbon offset labels for the projects providing the carbon offsetting. We conducted individual interviews and elicited feedback from local experts (i.e., decision-makers, those with expert knowledge on the systems and stakeholders) on multiple occasions to appraise the merits of specific certification projects. Through the application of several participatory processes, we developed a comprehensive decision model that included all the aspects that these local experts considered important in assessing the impacts of certification. We subjected these same experts to calibration training, to enable them to provide probability distributions for all input parameters in the form of estimated confidence intervals. We ran the final decision model as a Monte Carlo simulation to project plausible ranges of decision outcomes, expressed as Net Present Values (NPV) and annual cash flows. We identified critical 
uncertainties and important variables for further research using model sensitivity and value of information analysis.

We aim to showcase a methodology that can determine whether the positive social, ecological, and economic benefits outweigh the costs and risks involved in establishing and maintaining the certification. We demonstrate the application of these methods to the decision of extending an existing reforestation as well as implementing a new agroforestry project in Costa Rica. Both projects involve replanting degraded arable land with native and naturalized tree species, but the agroforestry project combines the replanting with cultivating ginger on the same area. We focused our decision model to determine whether the positive social, ecological, and economic benefits of certification are likely to outweigh the economic expenses of (a) certifying an additional reforestation site as a new area within an existing certification scheme and (b) carrying out a new certification process for an agroforestry site.

\section{Materials and methods}

\subsection{Study area and setting}

Since 2007, the project network FuturoVerde has been engaged in environmental activities in Costa Rica. The two German companies BaumInvest AG and PuroVerde eG are parts of the project network, implementing reforestation and agroforestry projects in the Alajuela Province together with their partner companies in Costa Rica (Querdenker GmbH 2017). BaumInvest AG is an unlisted stock corporation, aiming to combine sustainable reforestation while generating financial returns for the investors (https://www.bauminvest.de/). For their reforestation activities, the company purchases abandoned or unused pastureland, or land from retired farmers where no direct successors in the next generation would carry on the farm activities. The land is then owned by the stock corporation, whose investors are all shareholders or respectively limited partners that hold voting rights according to the size of their company share (Rock 2016). PuroVerde eG is a registered cooperative of consumers, traders, and producers who jointly invest in the development, cultivation, and marketing of tropical products from permaculture and forestry. The cultivation sites are owned by the cooperative, whose members receive a portion of the profits depending on the size of the business share they hold (https://puroverde.de/die-genossenschaft/). In terms of ownership structure, the sites therefore differ from reforestation or agroforestry projects that are often owned by smallholders (Manaye et al. 2021). We built two simulation models to cover the costs, benefits, risks, and uncertainties of two certification decisions for BaumInvest AG and PuroVerde eG.

- Decision a: In 2010 BaumInvest AG certified 150 ha of their reforestation sites with the CarbonFix standard. CarbonFix was purchased by the Gold Standard in 2012 (The Redd Desk 2014). At present, BaumInvest AG is considering the addition of another 375 ha within the already existing certification framework according to the "new area" scheme of the Gold Standard (The Gold Standard 2018). The area is reforested with different combinations of the native and naturalized tree species Dipteryx oleifera Benth. (tonka bean), Vochysia ferruginea Mart. (botarrama), Swietenia macrophylla King. (Honduran mahogany), Vochysia guatemalensis Donn. (cebo), Cedrela odorata L. 
(Spanish cedar), Hymenaea courbaril L. (West Indian locus), Cordia alliodora (Ruiz \& Pav.) Oken (Spanish elm), Hieronyma alchorneoides Allemão (pilón), and Tectona grandis L. (teak).

- Decision b: PuroVerde eG plans to extend its currently small ginger (Zingiber officinale) production into a much larger agroforestry project. Certifying the agroforestry sites under the "Gold Standard A/R GHG Emissions Reduction \& Sequestration Methodology" (The Gold Standard 2017), the same certification applied to BaumInvest AG's reforestation sites, could offer additional benefits for PuroVerde eG. The agroforestry project will include ginger cultivation in combination with native and naturalized tree species, which have not yet been specified.

The "Gold Standard A/R GHG Emissions Reduction \& Sequestration Methodology" sets the framework for the certification. The methodology is applicable for projects that include the planting of trees on land that does not meet the definition (of the Designated National Authority of the project's host country) of a forest at the beginning of planting. This document provides guidelines for afforestation and reforestation projects, defining certain environmental standards that must be met as well as a methodology for the calculation of $\mathrm{CO}_{2}$ fixation by forests.

The agroforestry and reforestation sites are located in the Alajuela Province in northern Costa Rica. Annual precipitation throughout the region ranges from 3500 to $4000 \mathrm{~mm} / \mathrm{year}$ and the mean annual air temperature is $25^{\circ} \mathrm{C}$. The regions where the projects are implemented are characterized by clayey Inceptisol and Ultisol soils (Sherman and Brye 2019).

\subsection{Decision Analysis approach}

The Decision Analysis methods we used were inspired by the Applied Information Economics approach developed by Hubbard Decision Research (Hubbard 2014) and research projects conducted by Luedeling et al. (2015), Whitney et al. (2017), and Lanzanova et al. (2019).

A crucial first step in the Decision Analysis process is to focus on a decision, with precisely formulated alternative options, for which a rational recommendation is to be made (Luedeling and Shepherd 2016). We defined the decision questions with the research managers of both the agroforestry and the reforestation projects. The decisions were then confirmed by the relevant board members of the companies. In order to assess the current state of knowledge on all uncertain factors involved in the decisions, we conducted a literature review of relevant Gold Standard documents and current research on voluntary carbon offset labels and related topics. A central principle of Decision Analysis is the inclusion of the existing knowledge of local experts in the model development process. By local experts, we refer to decision-makers, those with expert knowledge on the systems and other stakeholders. We therefore conducted several rounds of interviews in Costa Rica and in Germany, each with one or two experts from the project network. Interviews were conducted either in Spanish or German, depending on the native language of the interviewees.

We developed the decision model by working with local experts through several interview and modeling stages (Fig. 1). The companies BaumInvest AG and PuroVerde eG are based in Germany, where the first round of interviews took place. We worked with members of the two companies to identify relevant factors that could affect the decisions and described the corresponding causal mechanisms. We aimed to consider all aspects of relevance to the decisions, regardless of whether the parameters could easily 


\section{Interview and modeling stages}

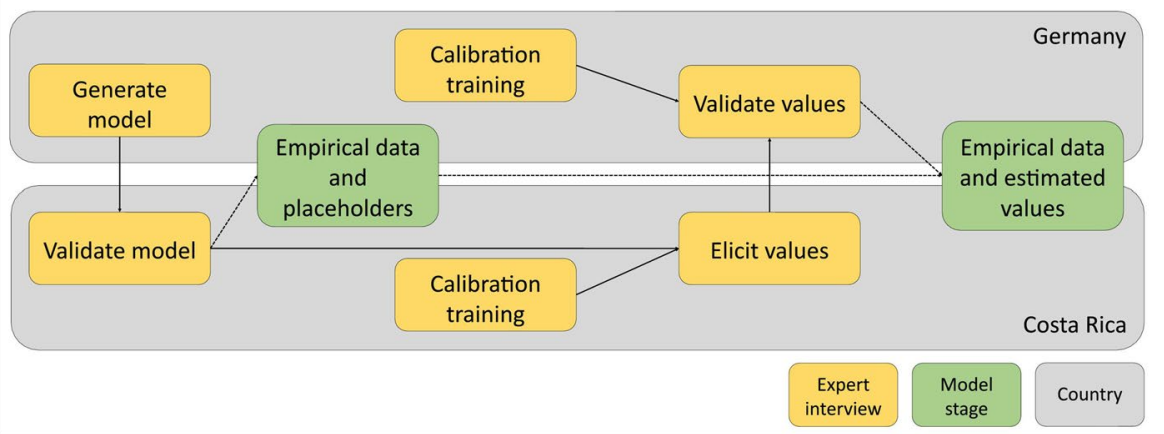

Figure 1 Interview and modeling stages for the development of a decision model for the decision to certify a reforestation and an agroforestry project in Costa Rica with the voluntary carbon offset label Gold Standard

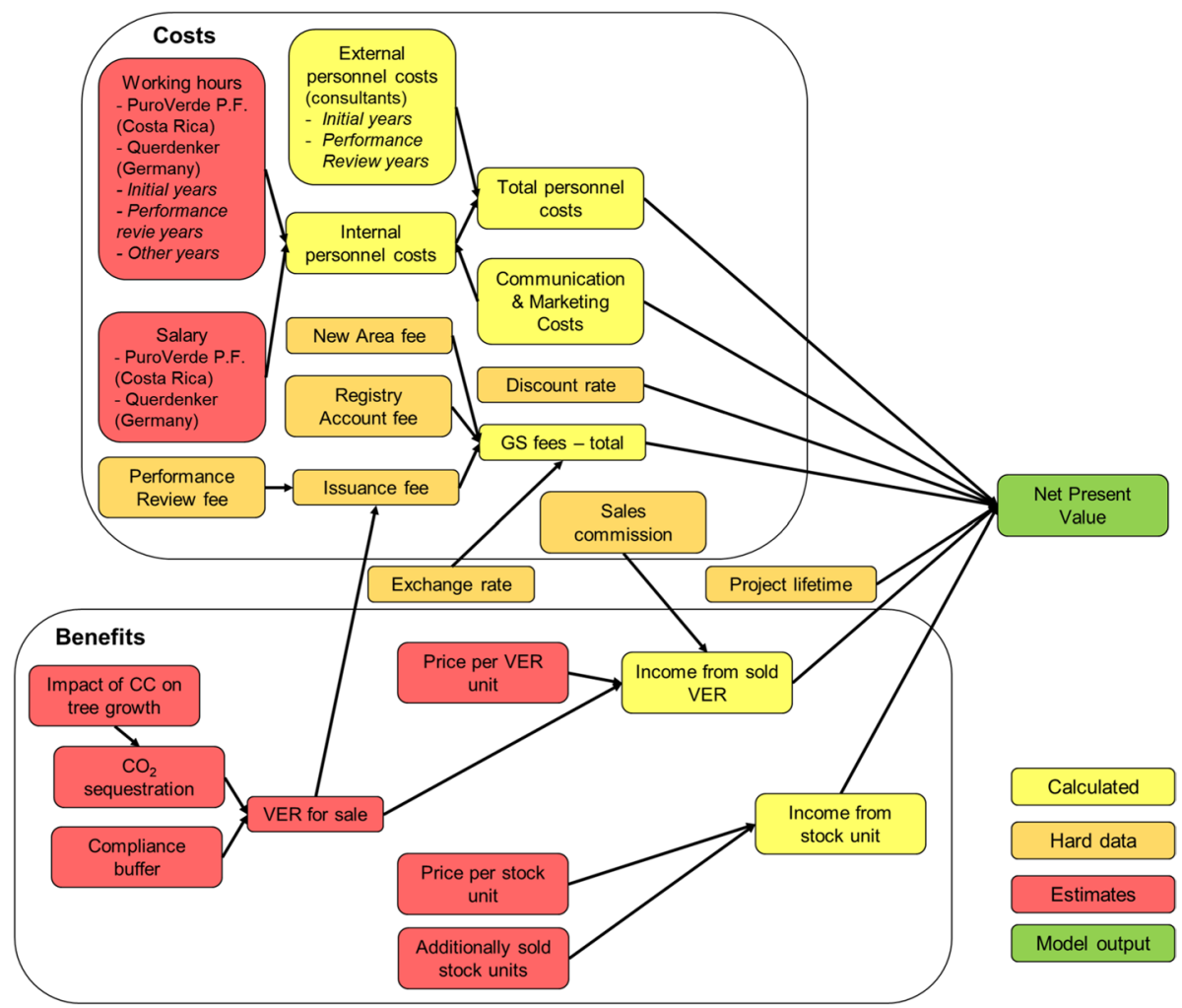

Figure 2 Input variables and overall model structure for the Decision Analysis of certifying a reforestation project in Costa Rica with the Gold Standard (GS) and selling Verified Emission Reductions (VER) under the impact of climate change (CC) 
be measured or modeled. We translated the factors and their relationships into a graphical model (Fig. 2). We validated the model and verified and completed the list of input variables in a second round of interviews in Costa Rica. The information retrieved from the interviews and the literature review was then reformulated as a set of equations that reflected as much as possible the experts' and analysts' understanding of the decision. We coded the mathematical models as a first draft of a function in the programming language R (R Core Team, 2018), using several functions from the R package "decisionSupport" (Luedelinget al. 2019). Wherever possible, we used empirical data to generate priors describing the variable values (e.g., for the Gold Standard fees). Where no data were available, placeholders were used for the first run of the model.

For those input parameters for which no empirical data were available, we elicited values from appropriate experts within the project network in both Costa Rica and Germany.

Before value estimates were elicited from the experts, participants were subjected to calibration training, a well-established methodology to raise experts' ability to estimate their own state of uncertainty (Hubbard 2014). The training included trivia questions and equivalent bet tests. This training raised the experts' capacity to provide reliable ("calibrated") estimates of $90 \%$ confidence intervals (i.e., they were $90 \%$ confident that the provided range included the correct value) in the form of upper and lower bounds for the variable values (Hubbard 2014). While calibration training is often carried out with groups of experts (Lanzanova et al. 2019; Luedeling et al. 2015), we conducted it on an individual basis. This allowed us to adapt the calibration training to the needs and skills of each person. Furthermore, the individual trainings helped us to manage our time and resource constraints, which did not allow us to hold joint calibration workshops with all experts. We consolidated all calibrated estimates into one single probability distribution for each model parameter (Luedeling et al. 2015). To reconcile variable estimates from multiple experts, we aggregated all individual assessments by consensus. This approach aims to overcome the risk of losing important information caused by averaging, an often-preferred strategy (Lyon et al. 2015). If no empirical data were available and no experts could be identified (e.g., for the carbon sequestration potential of agroforestry sites), we retrieved the value ranges for the variables from the literature.

Once we had gathered values for all input variables (empirical data, calibrated estimates, and value ranges from the literature), we ran the final decision models 10,000 times as a Monte Carlo simulation, with each run providing one possible outcome. The decision outcomes were expressed as Net Present Values and annual cash flows. The totality of all model runs converted the probabilistic inputs into a probability distribution of outputs that expressed the range of plausible decision results, given the experts' current state of uncertainty.

We conducted a sensitivity analysis to assess the extent to which the various input uncertainties affected the project outcome estimates, i.e., the key uncertainties in the decision-making process of the project. We applied Partial Least Squares (PLS) regression to identify the variables that the decision model outputs were most responsive to. As a metric providing a quantitative estimate of the effect each individual variable has on the decision outcomes projected by the simulation, we used the Variable Importance in the Projection (VIP) score (Luedeling et al. 2015; Luedeling and Gassner 2012; Wold 1995). Furthermore, we calculated the Expected Value of Perfect Information (EVPI) to identify priorities for decision-specific research. The EVPI expresses what a rational decision-maker should be willing to pay to gain access to perfect information (Luedeling and Shepherd 2016). 


\section{Results}

\subsection{Crediting period and project lifetime}

Together with the experts, we identified time-dependent characteristics and processes over the life span of the projects and integrated them into the model. In accordance with the experts, we assumed that completing the certification of the agroforestry and the reforestation project would take 2 years. In line with the Gold Standard requirements, we assumed a crediting period of 30 years for the agroforestry project, during which VER can be earned and marketed (The Gold Standard 2018). We set the simulated project lifetime of the agroforestry project to 32 years. Gold Standard audits, the so-called performance certifications, take place every 5 years. The Gold Standard fees (covered by the two companies PuroVerde $\mathrm{eG}$ and BaumInvest $\mathrm{AG}$ ) as well as the time required to maintain the certification (and therefore the model) differ between non-performance certification and performance certification years. After 2 years of preparation, the reforestation project would be added as a new area to the existing certification scheme in 2022 during a performance certification. Since the crediting period of the already certified reforestation sites ends in 2036, the crediting period of the newly added sites would be 15 years, with a project lifetime of 17 years. Performance-certifications would take place in years 7, 12, and 17 of the project lifetime.

\subsection{Marketing strategies}

The experts considered several marketing strategies for the VER generated by the agroforestry project to be feasible. Together, we defined three marketing strategies and analyzed the outputs of an adapted version of the agroforestry decision model for each option. The generated VER could either (1) be put on hold to sell carbon-neutral agricultural products instead, (2) be sold directly, or (3) be passed on to company shareholders, who could either sell the VER or offset their own emissions by putting them on hold.

\subsection{Return on investment}

\subsubsection{Agroforestry project-marketing strategy (1) sale of carbon-neutral products}

The cash flow analysis of the sale of carbon-neutral products illustrates that substantial initial investments are incurred during the first 3 years of the project (Fig. 3). Furthermore, only costs are incurred during this time, while no benefits are obtained, as VER can only be sold after completing the certification in year 4 . Therefore, the median of the $90 \%$ confidence interval (CI, probability that a parameter will fall between a pair of values around the mean) of the cash flow predicted by the decision model is negative in years 1 and 2, at $-13,000$ and $-16,000$ EUR respectively. In year 3, the highest investment costs are incurred, and the median of the cash flow drops to - 265,000 EUR. Due to the growth of the project area, the number of VER per year increases over the project lifetime, and the cash flow grows from a median of 60,000 EUR in year 4 to 79,000 EUR in year 31 . Dents in the cash flow occur in years $7,15,22,27$, and 32 , which correspond to the frequency of the performance certification years we had calculated. From year 4 until the end of the crediting period, the lower bound of the $90 \% \mathrm{CI}$ of the cash flow is positive in 


\section{Cashflow of agroforestry project}

Carbon neutral products

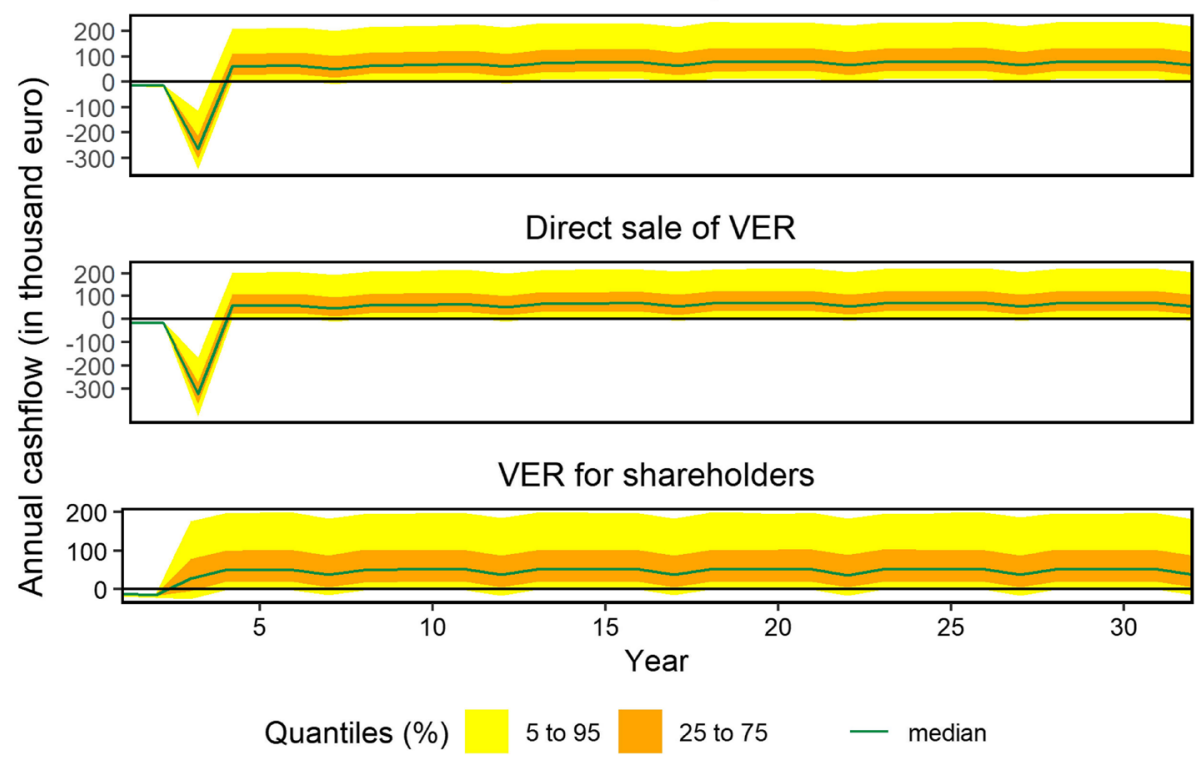

Figure 3 Cash flow outputs of a Monte Carlo simulation (with 10,000 model runs) for ex-ante analysis of the decision to certify an agroforestry site in Costa Rica with a voluntary carbon offset label, with three marketing strategies: (1) Sale of carbon-neutral products, (2) Direct sale of Verified Emission Reductions (VER), (3) Pass VER on to company shareholders. Plots show the projected probability distributions of the annual cash flows

all non-performance-certification years. In the performance-certification years, where additional fees and staff time are required, the lower bounds of the $90 \%$ CI (i.e., the $5 \%$ quantile) of the cash flow become negative, ranging between -9000 EUR in year 7 and -4000 EUR in year 27. The median of the cash flow range is slightly lower in performance-certification years than in normal years, but still positive (between 50,000 in year 7 and 65,000 EUR in year 32). While the range between the lower and upper bounds (the 5\% and 95\% quantiles) of the cash flow is quite narrow in years 1 and 2 (difference of 10,000 EUR), the difference between the bounds is around 220,000 EUR in the following 30 years.

The NPV of the sale of carbon-neutral products lies within a 90\% CI between -230,000 and 3.4 million EUR, with a median of 848,000 EUR (Fig. 4). With this marketing strategy for the VER, the chance of a negative NPV, i.e., a loss, is $14 \%$, the chance of gain is accordingly $86 \%$ for the project.

\subsubsection{Agroforestry project-marketing strategy (2) direct sale of VER}

Similar to the sale of carbon-neutral products, the strategy to directly sell the VER has high investment costs before the start of the crediting period and high marketing costs in year 3 . The initial costs are reflected in the negative cash flow in the first 3 years of the project lifetime (Fig. 3). For the direct sale of VER, the median of the $90 \% \mathrm{CI}$ of the cash flow is $-13,000,-16,000$, and $-325,000$ EUR in years 1,2 , and 


\section{Net Present Value of agroforestry project}

Carbon neutral products

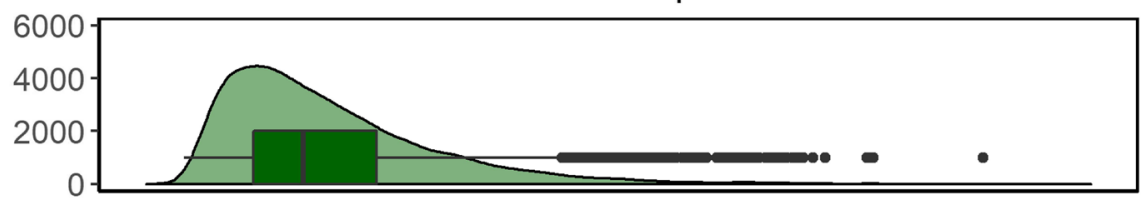

Direct sale of VER

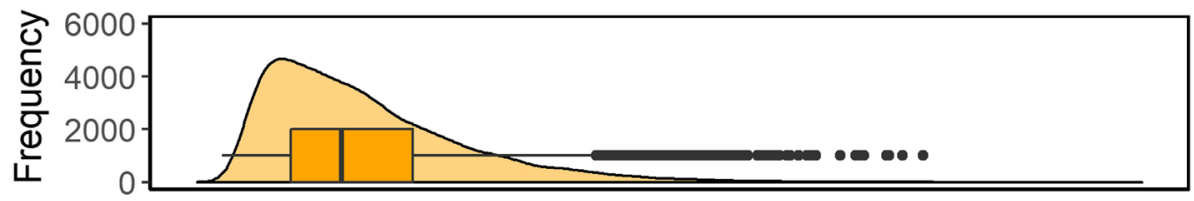

VER for shareholders

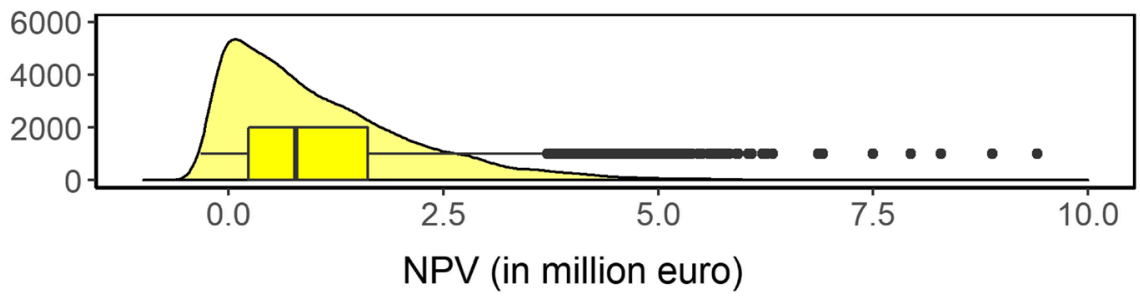

Figure 4 Outputs of a Monte Carlo simulation (with 10,000 model runs) for ex-ante analysis of the decision to certify an agroforestry site in Costa Rica with a voluntary carbon offset label, with three marketing strategies: (1) Sale of carbon-neutral products, (2) Direct sale of Verified Emission Reductions (VER), (3) Pass VER on to company shareholders. Plots show the projected probability distribution of the Net Present Value (NPV) across all the simulation runs. The boxplot indicates the median, $25 \%$ and $75 \%$ quantiles, and outliers of those results

3 , respectively. The increasing median of the cash flow range reflects the increasing number of VER that is generated through the growth of the project area, showing similarities to the sale of carbon-neutral products. After year 3, the median of the cash flow increases slightly from around 57,000 EUR in year 4 to 70,000 EUR in year 31 and is positive in all non-performance-certification years. In the performance-certification years, the cash flow ranges between 46,000 EUR in year 7 and 57,000 EUR in year 32 (end of the crediting period). The difference between the lower and upper bound of the cash flow is 10,000 EUR in years 1 and 2. From year 3 on, the difference between the lower and upper bound of the cash flow fluctuates around 21,000 EUR, similar to the sale of carbon-neutral products.

The NPV of the direct sale of VER lies, with $90 \%$ confidence, between $-342,000$ and 3.2 million EUR, with a distribution median of 687,000 EUR (Fig. 4). While the upper bound is similar to the sale of carbon-neutral products, the lower bound and the median of the NPV of the direct sale of VER are slightly lower than for the sale of carbon-neutral products. The chance of a loss is $20 \%$ for the project, if the direct sale of VER is chosen. 


\subsubsection{Agroforestry project-marketing strategy (3) pass VER on to company shareholders}

The cash flow of the strategy to pass the VER on to company shareholders is negative in the first 2 years of the project, with a median of the $90 \%$ CI of $-13,000$ EUR in year 1 and $-16,000$ EUR in year 2, similar to the sale of carbon-neutral products and the direct VER sale (Figure 3). The positive median of the cash flow in year 3 (28,000 EUR) reflects the lower initial investment costs (especially in the area of marketing) of passing VER on to the shareholders, compared to the other two strategies. Unlike when selling carbon-neutral products or the VER directly, the median of the cash flow range of passing the VER on does not increase after year 3, but stabilizes around 51,000 EUR, slightly lower than the median of the other two marketing strategies. As neither VER nor carbon-neutral products are sold, the increase of the certified area does not generate an income increase over the lifetime of the project. The median of the $90 \% \mathrm{CI}$ of the cash flow declines slightly in performance-certification years. It lies around 37,000 EUR in years 7, 12, 17, 22, 27, and 32. The difference between the lower and upper bound of the $90 \% \mathrm{CI}$ is around 10,000 EUR in years 1 and 2 and fluctuates around 200,000 EUR from year 3 until the end of the project lifetime. The $90 \%$ CI for the cash flow from year 3 onwards is considerably wider than the ranges of the other two strategies.

The NPV of the marketing strategy of passing VER on to company shareholders had a 90\% CI between - 130,000 and 3.2 million EUR, with a median of 783,000 EUR (Fig. 4). When passing VER on to the shareholders, the chance of a loss is $13 \%$ for the project.

\subsubsection{Agroforestry project-comparison of the three VER marketing strategies}

In case of the Gold Standard certification of the agroforestry project, the NPV distributions of all three VER marketing strategies have positive medians that do not differ significantly (Fig. 4). The sale of carbon-neutral products, however, has a slightly higher median than both the direct sale of VER and passing them on to the company shareholders. The probabilities of net losses when selling carbon-neutral products and passing VER on to shareholders are quite similar, while the direct VER sale has a slightly higher risk of a negative NPV. The direct sale of VER has the highest investment costs of all three strategies, showing the lowest median of the cash flow range in year 3 . The median of the cash flow range of the sale of carbon-neutral products also reaches its low point in year 1, but is slightly higher than the direct VER sale option. Passing the VER on to the company shareholders is the strategy with the lowest investment costs. The low median cash flow (achieved in year 2) of passing the VER on to the shareholders is higher than in the other two strategies (not achieved until year 3) (Fig. 3).

\subsubsection{Reforestation project}

The cash flow range of the reforestation project (Fig. 5) reflects the low initial investment costs and shows a positive median in year 1 (9000 EUR) and year 2 (8000 eight EUR). In year 3, marketing and communication costs are incurred, and the certification process is completed. VER from the three previous years can be sold in addition to the VER generated in the year of the certification due to a retroactive issuance scheme of the Gold Standard (The Gold Standard 2018). The cash flow is therefore clearly positive in year 3. 


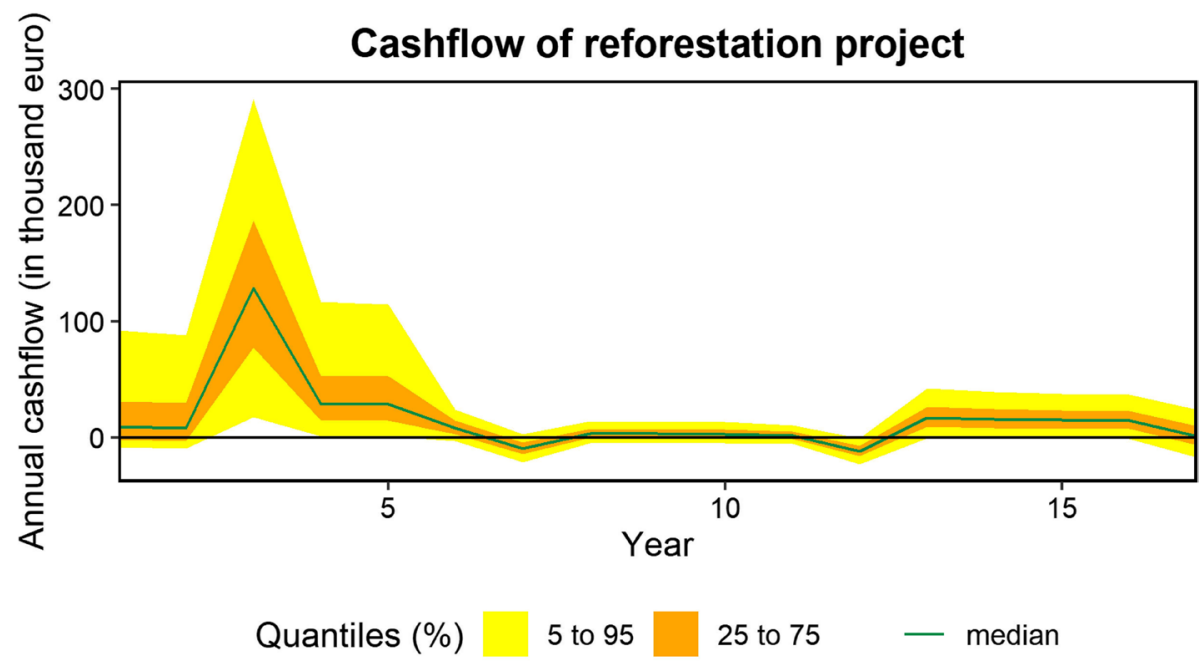

Figure 5 Outputs of a Monte Carlo simulation (with 10,000 model runs) for ex-ante analysis of the decision to certify a reforestation site in Costa Rica with a voluntary carbon offset label. The plot shows the projected probability distribution of the annual cash flow

The median of the $90 \%$ CI of the cash flow is 127,000 EUR in year 3, the highest median throughout the project lifetime. The median of the cash flow remains positive in all nonperformance-certification years, with negative values occurring in the performance-certification years 7 (-10,000 EUR) and 12 (-12,000 EUR). In the last performance-certification year (year 17), the median of the cash flow range is 1000 EUR. Throughout the years of the project lifetime, the cash flow range shows high variability, reflecting the harvest and reforestation cycles of the reforestation site, which change the number of available VER. In non-performance-certification years, the median of the cash flow range decreases from 28,000 EUR to 1000 EUR between years 4 and 11, then increases to 17,000 EUR in year 13 before decreasing again to 15,000 EUR in year 16 .

The NPV of the certification for the reforestation project lies with a $90 \%$ CI between $-29,000$ and 750,000 EUR, with a median of 252,000 EUR (Fig. 6). The chance of a negative NPV, i.e., a loss, is $7 \%$ in case of the certification of the reforestation project.

\subsection{Sensitivity analysis}

\subsubsection{Agroforestry project-marketing strategy (1) sale of carbon-neutral products}

Sensitivity analysis indicated that three variables had an important effect on the outcome of the simulation (NPV and cash flow) in case of the Gold Standard certification of the agroforestry project with marketing strategy (1) "Sale of carbon-neutral products." Variables are commonly considered important when their VIP values exceed 0.8 (Luedeling and Gassner 2012). The variable "Additional shares sold," an indirect benefit of the certification, has the highest VIP of all variables, with a score of 4.2 (Fig. 7; Table 1). The impact of using the generated VER to create carbon-neutral products is reflected in the VIP of the variable "Additional product sales," which has a score of 


\section{NPV of reforestation project}

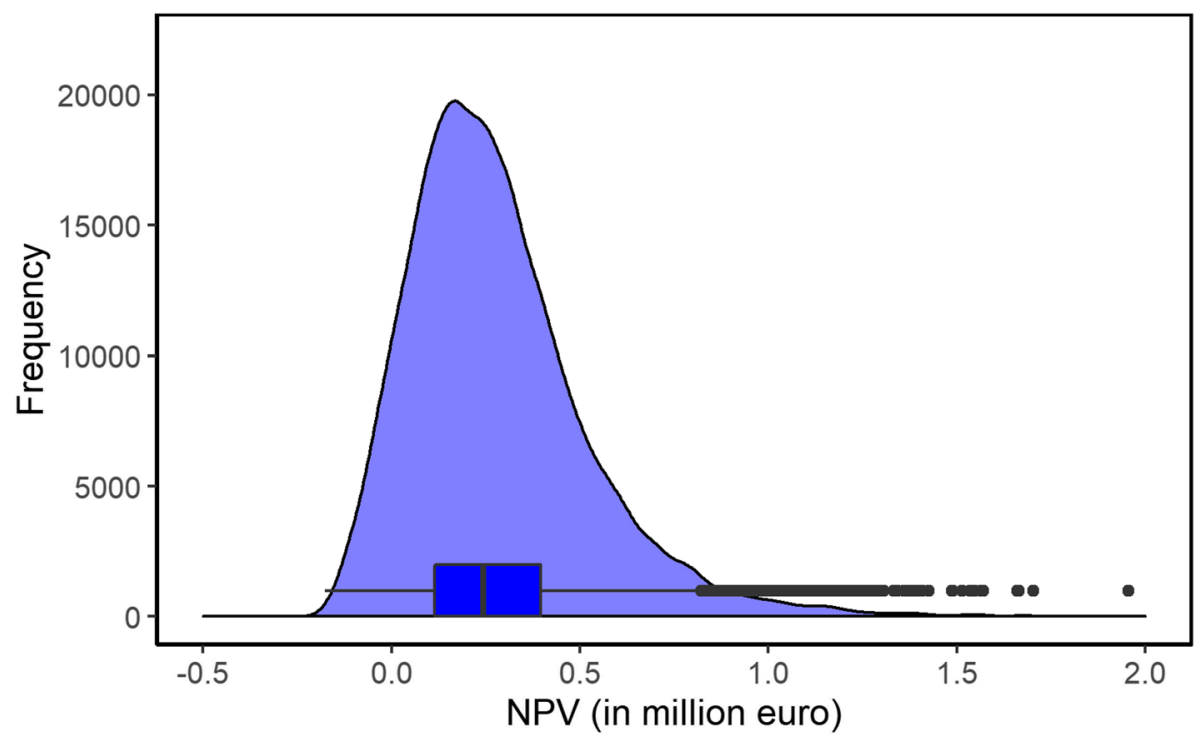

Figure 6 Outputs of a Monte Carlo simulation (with 10,000 model runs) for ex-ante analysis of the decision to certify a reforestation site in Costa Rica with a voluntary carbon offset label. The plot shows the projected probability distribution of the Net Present Value (NPV) across all the simulation runs. The boxplot indicates the median, $25 \%$ and $75 \%$ quantiles, and outliers of those results

1.17. The last variable with an important effect on the outcomes is the "Discount rate," although its VIP score of 0.95 indicates a much lower importance than the "Additional shares sold." For the direct sale of VER, "Additional shares sold" is the only variable with a non-zero EVPI in case of project implementation (Fig. 7), indicating a possible priority for decision-specific research. The EVPI of the variable is 2000 EUR, which corresponds to what a rational decision-maker should be willing to pay to obtain perfect information on the variable.

\subsubsection{Agroforestry project-marketing strategy (2) direct sale of VER}

Three input variables are considered important for the outcome of the direct sale of VER. Similar to the sale of carbon-neutral products, the variable "Additional shares sold," an indirect benefit of the certification, has the highest impact on the outcome of the simulation, with a VIP score of 4.28 (Fig 7; Table 1). The VIP score of "Carbon dioxide sequestration" is 0.86 , indicating that the direct certification benefits of being able to sell the generated VER have an important, but much smaller impact than the indirect benefits. The third variable that is considered important is the "Discount rate," with a VIP score of 0.83 . "Additional shares sold" is the only variable with a non-zero EVPI under this strategy 2) "Direct sale of VER" (Fig. 7). The EVPI of the variable is 9000 EUR. 


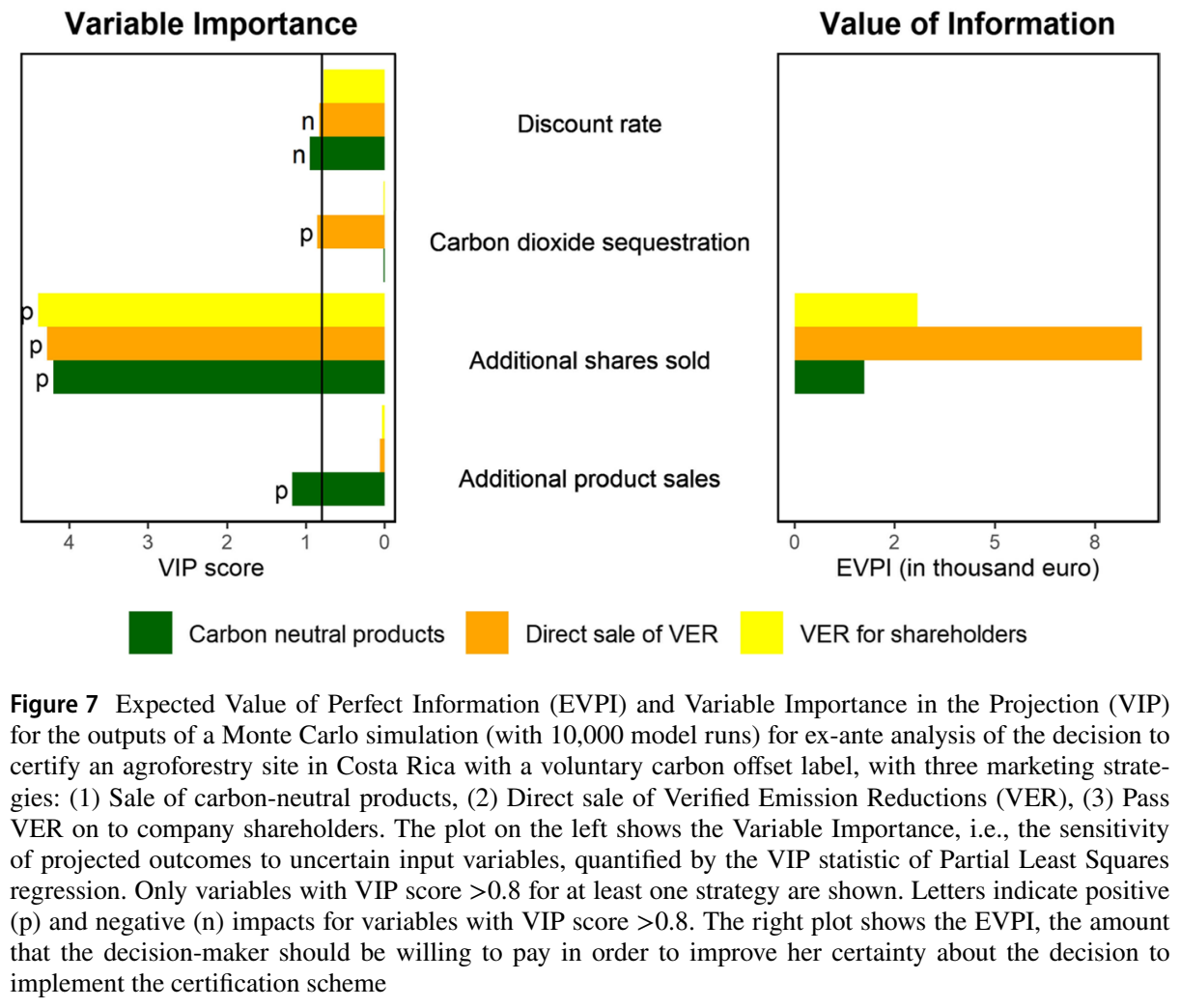

\subsubsection{Agroforestry project-marketing strategy (3) pass VER on to company shareholders}

Marketing strategy (3) "Pass VER on to company shareholders" is primarily focused on the indirect benefits, as the VER are neither sold nor used for carbon-neutral products but given to the shareholders. This approach is reflected in the VIP score of 4.4 of the variable "Additional shares sold" (Fig. 7; Table 1). It is the only variable with a VIP score above 0.8 for passing the VER. Similar to the sale of carbon-neutral products and the direct VER sale, "Additional shares sold" is the only variable with a non-zero EVPI (Fig. 7). The variable has an EVPI of 3000 EUR.

\subsubsection{Reforestation project}

Sensitivity analysis indicated that the output of the model was sensitive to the variables "VER price" (VIP = 3.42) and "additional stock sales" (VIP = 2.39) (Table 2). The two variables reflect the impact of both the direct and the indirect benefits of the certification (Fig. 8). The VER price is related to the benefits from the direct VER sales, while the additional stock sales are the indirect outcome of the impact the certification has on the shareholders' willingness to purchase shares. The only variable with a non-zero EVPI was "VER price." The calculation indicates that the decision-maker should be willing to pay 


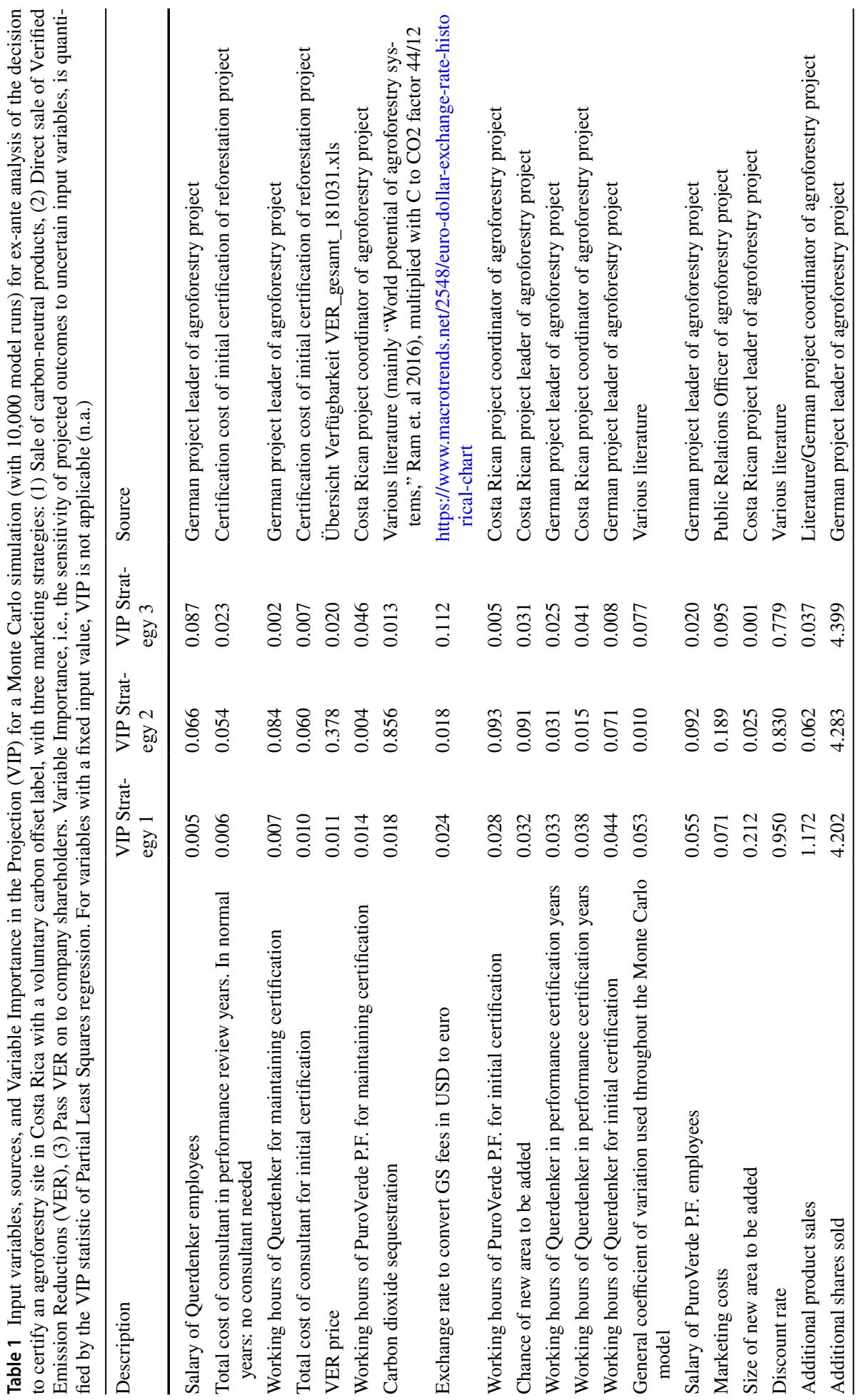




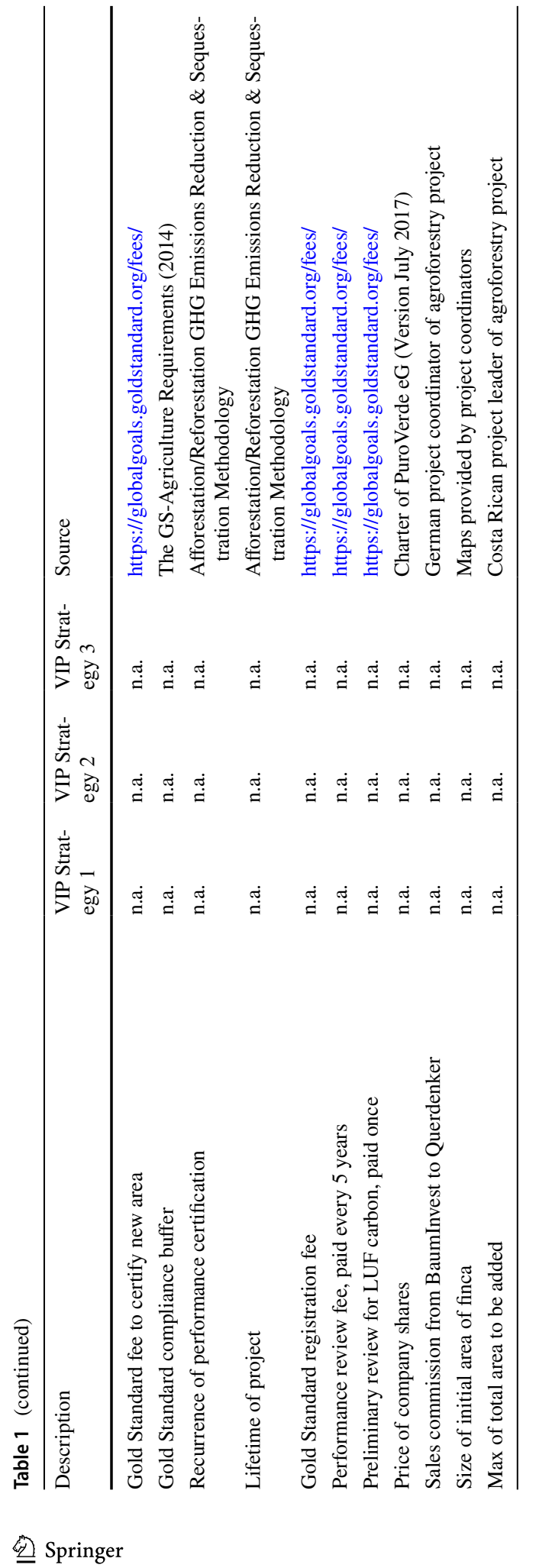




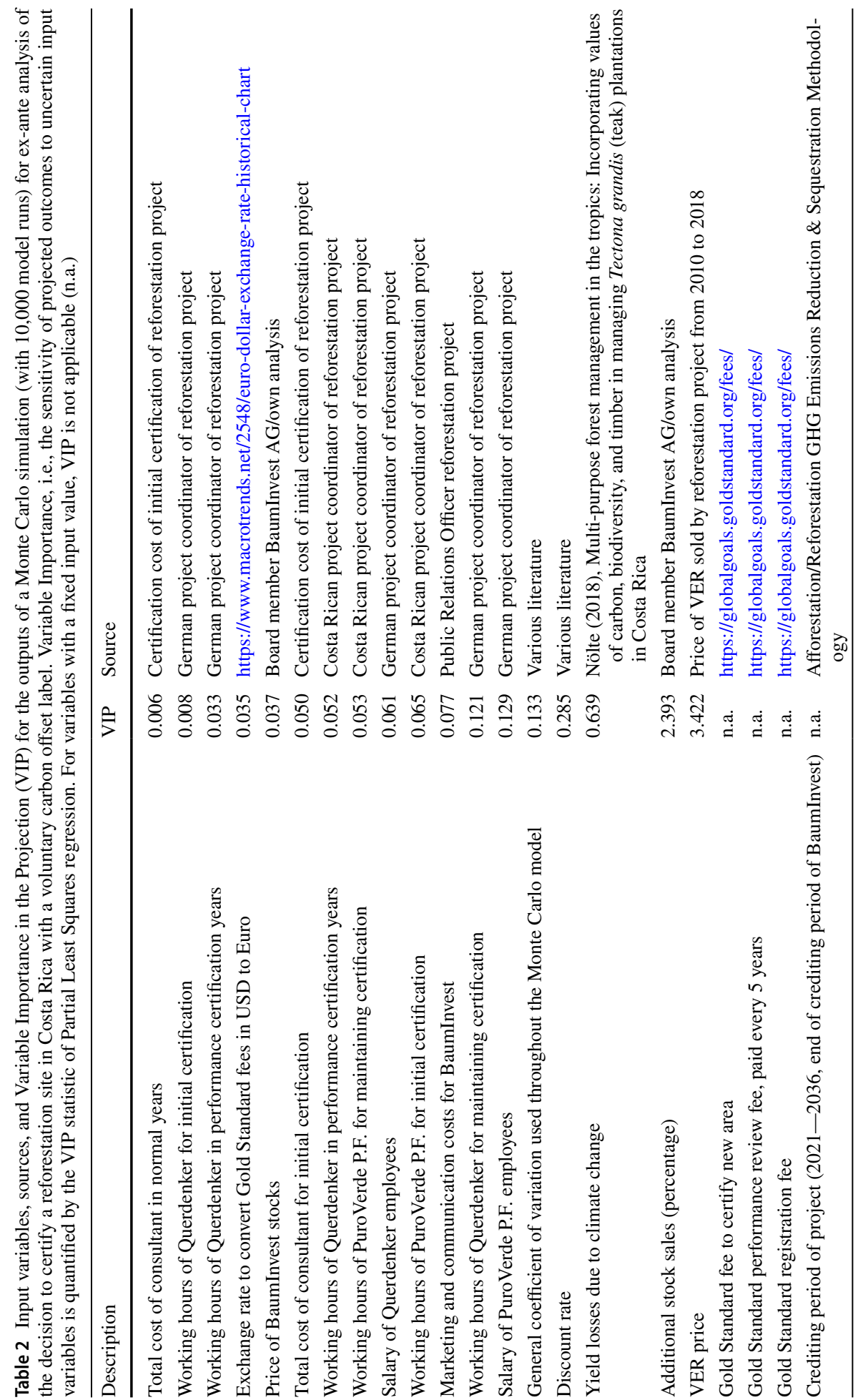




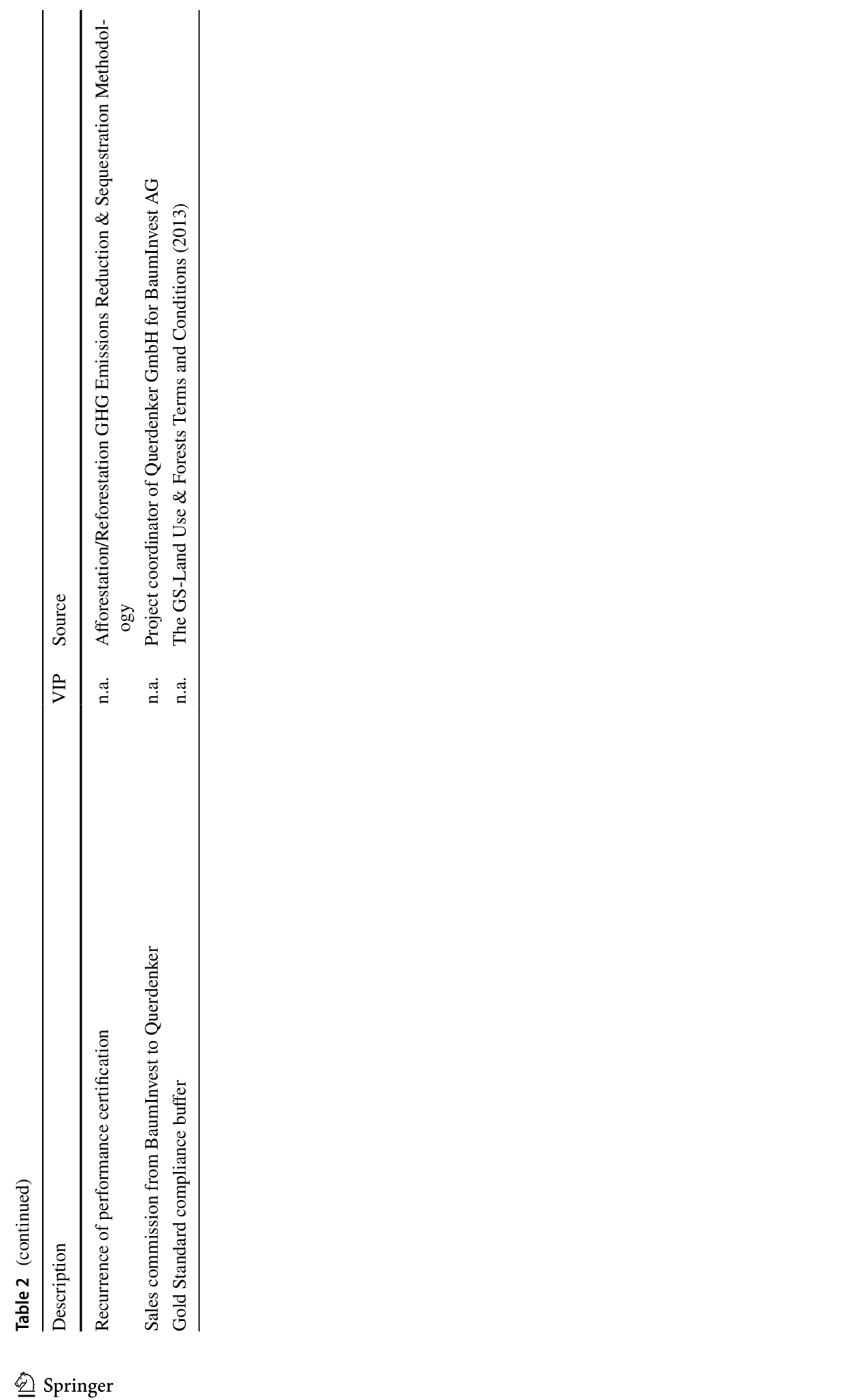


Variable Importance

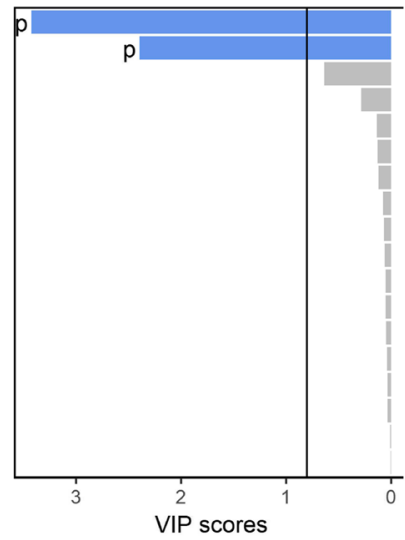

Value of Information

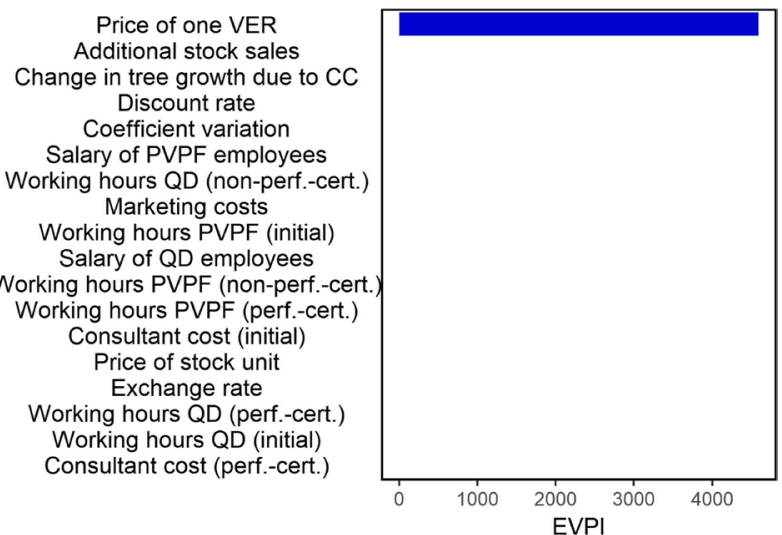

Figure 8 Expected Value of Perfect Information (EVPI) and Variable Importance in the Projection (VIP) for the outputs of a Monte Carlo simulation (with 10,000 model runs) for ex-ante analysis of the decision to certify a reforestation site in Costa Rica with a voluntary carbon offset label. The plot on the left shows the Variable Importance, i.e., the sensitivity of projected outcomes to uncertain input variables, quantified by the VIP statistic of Partial Least Squares regression (blue: VIP $>0.8$, gray: VIP $<0.8$ ). Letters indicate positive (p) impact for variables with VIP score $>0.8$. The right plot shows the EVPI, the amount that the decision-maker should be willing to pay in order to improve his or her certainty about the decision to implement the certification scheme. VER Verified Emission Reductions, CC climate change, PVPF Puro Verde Paraíso Forestal, QD Querdenker

up to 3000 EUR to learn more about the effect of this variable on the decision outcome (Fig. 8).

\section{Discussion}

\subsection{Return on investment}

\subsubsection{Agroforestry project-comparison of the three VER marketing strategies}

Model results suggest that all three VER marketing strategies for a Gold Standard certification of the agroforestry project are likely to lead to additional profit. For all strategies, the chance of loss when investing in certification is lower than the chance of opportunity losses of operating without certification. Implementing certification with one of the strategies therefore seems sensible. The choice of VER marketing strategy depends on the priorities and preferences of the decision-makers. While establishing a preference between the sales of carbon-neutral products and passing the VER on to the company shareholders, the direct sale of VER clearly emerged as the least advisable. The direct sale of VER has the lowest median NPV, the highest probability of loss, and no clear advantages compared to the other two strategies. A key reason for the low benefits of direct VER sale might be the low carbon sequestration potential of agroforestry projects compared to forestry projects (FAO 2016). The low additional income of directly selling VER confirms the importance of evaluating a project's specific setting before considering a particular certification scheme, mirroring conclusions drawn 
in many earlier studies (Fischer et al. 2017; Hamrick and Gallant 2017; Kollmuss et al. 2008; Tienhaara 2012). Most studies that have analyzed the framework of carbon offsetting indicate potential economic benefits for participating projects, but also acknowledge the scarcity of empirical studies on the actual impact on these projects (ICROA 2014; Kollmuss et al. 2008).

Both the sale of carbon-neutral products and passing VER on to company shareholders have certain advantages. Selling carbon-neutral products seems to have the highest return on investment in the long run, as it has the highest median NPV, and the lowest probability of loss. The positive return on investment confirms the results of several studies that report a high willingness-to-pay for carbon-labeled products among consumers, which led to an overall positive impact on company incomes (Feucht and Zander 2018; Kim et al. 2016; Vecchio 2013; Vecchio and Annunziata 2015). An applied example of the sale of carbon-neutral products is the Gold Standard-certified company ForestFinest, which puts VERs generated by their cocoa tree plantations on hold to produce "climate positive" chocolate (Sommer-Guist and Assenmacher 2015). The additional income generated by selling carbon-labeled products, however, often benefits downstream manufacturers rather than the landowners and farmers cultivating the raw materials (such as cocoa) (Mithöfer et al. 2017).

The NPV and the probability of gain are slightly lower for passing VER on to shareholders than for the sale of carbon-neutral products. A clear advantage of passing the VER on to shareholders are the significantly lower investment costs in year 3, a result of the lower marketing costs (compared to the direct sale of VER and carbon-neutral products). This is particularly important, as low liquidity during the initial years is a challenge for the agroforestry project.

\subsubsection{Reforestation project}

The outcome of the decision model for the reforestation project (a low probability of loss and a positive median NPV) suggests that a Gold Standard certification of the reforestation sites would lead to additional benefits for the reforestation project. The chance of loss when investing in certification (7\%) is lower than the chance of opportunity losses of operating without certification. It is therefore advisable for the reforestation project to make the investment. The additional income for the project confirms the potential of certifying reforestation projects that many studies have identified (ICROA 2014; Kollmuss et al. 2008; Wright et al. 2000). The clearly positive cash flow during the first 6 years after the initial certification could contribute to closing the current liquidity gap that poses a challenge for the company. The potential negative cash flow in performance-certification years would, however, have to be compensated by other income sources of the company. Another concern is the decrease in cash flow from year 6 until the end of the crediting period due to the decreasing VER sales. Low replanting rates after harvests in the current management plan cause decreases in carbon sequestration, reducing the amount of VER available for sale. Revising the current management and replanting scheme for the reforestation project could help to reduce the decline in carbon sequestration, and thus positively affect the cash flow. Measures for improvement might include genetic considerations when selecting germplasm and increasing resilience by fostering natural selection, ecological connectivity, and species associations. More attention could also be paid to matching species and provenances to future climate predictions for the area (Roshetko et al. 2018; Thomas et al. 2014). 


\subsection{Sensitivity analysis}

\subsubsection{Agroforestry project-comparison of the three VER marketing strategies}

The high VIP score and non-zero EVPI for all strategies indicate that the variable "Additional shares sold" is the most important across the marketing strategies of the agroforestry project. The high importance of the additionally sold company shares implies that the indirect benefits arising from the certification have a greater influence on the outcomes than the direct benefits. The low $\mathrm{CO}_{2}$ sequestration potential of agroforestry sites compared to forests, however, could be an explanation for the low importance of the VER sales even when sold directly (FAO 2016).

The value range for the additionally sold company shares was set quite widely in the process of estimating the input variables, as little knowledge about the impact of certification on the company shareholders was available. The high importance of the variable and the initially wide range are reflected in the EVPI, which ranked between 1.9 thousand and 7.3 thousand EUR for the three strategies. The decision-makers' rational willingnessto-pay to gain more knowledge on the variable is low compared to the overall value of the decision. Even a small investment between 1.9 thousand and 7.3 thousand EUR could however help to increase certainty regarding the decisions. For example, conducting a survey among the current shareholders would be a simple way to obtain additional information on the effect that the Gold Standard certification would have on current and potential new shareholders. Gaining more knowledge, e.g., on the additionally sold company shares, would be beneficial for all of the marketing strategies, and could even help to better inform choices between the three options.

\subsubsection{Reforestation project}

While the two variables "VER price" and "Additional stock sales" can be considered important for the certification of the reforestation project (according to their VIP scores), only the VER price has a non-zero EVPI. The high importance of the VER price for the reforestation project corresponds to studies that see this variable as a major uncertainty factor for the whole VCM (Lang et al. 2018). Although the variable's EVPI of 3.5 thousand EUR is low compared to the overall value of the intervention, it is questionable whether more reliable information about this variable can be obtained at all. The VER price is highly volatile and strongly dependent on international policy-making. Predicting its future development with greater certainty is therefore challenging and resource-intensive, and it may well be impossible. Despite the non-zero EVPI of one variable, we are confident that the recommendation based on the model results are reliable. Given that the information value is relatively low, decision-makers of the reforestation project may still be able to make a fairly confident decision on the best investment option already based on model results with the current state of knowledge.

\subsection{Methodological limitations}

There is no guarantee that the model accurately captured all important aspects of the possible certification. While group workshops with all important stakeholders at once can be helpful when consolidating input parameters (Whitney et al. 2018), only individual 
interviews were possible in our research. However, differences in the experts' inputs mainly concerned the impact of the certification on managing the reforestation areas, and could mostly be resolved by consulting Gold Standard guidelines. Nevertheless, several interviewed staff members of the project network were not familiar with the Gold Standard certification and may have missed implications that certification could have. Although we did our best to complement the interviews with background literature, some variables may still be missing in the model. The model that emerged after several rounds of reviews nevertheless appeared quite comprehensive to all experts, and it included variables and indirect benefits that are often omitted in conventional cost-benefit analyses (Hubbard 2014). The high importance of the indirect benefits of certification (e.g., the impact on shareholders), which was revealed by the sensitivity analysis, is an indication of the advantages of probabilistic Decision Analysis.

A common concern about Decision Analysis is the ability of stakeholders to accurately estimate probability distributions for uncertain variables. Due to time and resource constraints, we did not provide in-depth calibration training that would meet the full recommendations of decision analysts (Hubbard 2014). However, our use of individual interviews might have helped to avoid typical biases of group interviews, such as anchoring effects (Kahneman 2011). Some variables remained difficult to estimate, even with extensive calibration training. Although we encouraged the experts to provide wide ranges whenever they were highly uncertain, they may still have been wrong in some cases. When retrieving values from the literature, we attempted to depict the range of all values found, but a certain risk of missing sources with values outside the ranges remains. However, we are confident that most estimates from literature and experts were appropriate for the simulation.

Given the context under which we designed the decision model, it is difficult to evaluate the impacts of any potentially missing variables or inaccurate estimates. The model describes a situation that has not arisen yet, which means that there is no observed data for validation. Even in the future, validating the model will remain difficult, as the model produces a wide range of possible outcomes. The decision on certification of the reforestation and the agroforestry projects may therefore have a wide range of outcomes without falsifying the model. However, the idea of Decision Analysis is not to provide a perfect prediction of an intervention's outcome, but to improve the information on which decision-makers base their choices (Luedeling et al. 2015). Even though the model remains, as every model, an imperfect and possibly incomplete reflection of reality, we used a structured analysis process and improved the decision-makers' current state of knowledge rather than dismissing relevant variables as unimportant or unpredictable.

\subsection{Applicability to other projects}

Eighty percent of the world's extremely poor (approximately 1.2 billion people), who are living on US\$1 or less a day, depend to some extent on forests (including agroforests and tree crops) for their income or livelihood, including through maintenance of soil fertility and water resources (The World Bank 2004). The legal structure of the projects assessed in our study, i.e., a stock corporation and a cooperative, is very different from such smallholder systems. Decision Analysis, however, does not claim to produce generally transferable outcomes when analyzing a particular project (Hubbard 2014). In this study, we aimed to provide a methodological tool to assess the risks and benefits of the certification of different kinds of projects, and this tool is generally also applicable to smallholder agroforestry systems. Due to the limited financial resources of smallholders, it is difficult 
to develop Decision Analysis models on the scale of an individual farm. When using the tool on a more general level, as done, e.g., by Whitney et al. (2017) to model the outcomes of the Ugandan government's agricultural development plan with regard to the nutritional value of home gardens, Decision Analysis can nevertheless be used to give recommendations for smallholder forestry and agroforestry systems.

\section{Conclusion}

We successfully applied Decision Analysis approaches to develop and apply a comprehensive simulation to support certification decisions in an agroforestry and a reforestation project in Costa Rica. Involving stakeholders as experts in this process allowed the generation of a realistic simulation that could provide guidance on the prospective net benefits of applying a Gold Standard certification. Our case study confirms that voluntary carbon offset labels can positively contribute to the liquidity of projects providing carbon credits. For both the agroforestry and reforestation options, we found a positive return on investment for certification with the Gold Standard. However, in comparison to other marketing strategies (selling carbon-neutral products and passing the VER on to shareholders), direct VER sales generated low additional income for the agroforestry project. The low income prospects of direct VER sales highlight the importance of ex-ante cost-benefit assessments before applying for certification. Since agroforestry projects offer a wide range of possible sale strategies, analyzing the individual risks and benefits of different marketing concepts is crucial. Directly selling VER can be a good option but may not guarantee the highest economic benefits for agroforestry projects, where identifying the needs and desires of consumers is crucial. The direct sale of VER led to a positive return on investment for the reforestation project in our study. However, well-developed management and replanting schemes are a central aspect for the success of carbon offset certification for reforestation projects. Developing these schemes requires a high level of analysis and knowledge, which can be provided under the umbrella of larger development projects to apply the approach to smallholders. Our work offers a practice-oriented, innovative approach to assess the possible return on investment, but also the risks of certification with a voluntary carbon offset label for individual projects.

Supplementary Information The online version contains supplementary material available at https://doi. org/10.1007/s11027-021-09992-z.

Acknowledgements We would like to show our gratitude to the staff of BaumInvest AG (former Querdenker $\mathrm{GmbH}$ ) and PuroVerde Paraíso Forestal S.A., who were kindly available for interviews and supported the data sampling process.

Funding Open Access funding enabled and organized by Projekt DEAL. The field work was made possible by an ASA program scholarship, funded by the German Federal Ministry for Economic Cooperation and Development.

Data availability and material The datasets generated and/or analyzed during the current study are available under the following link: https://doi.org/10.5281/zenodo.5602856

Code availability The datasets generated and/or analyzed during the current study are available under the following link: https://doi.org/10.5281/zenodo.5602856 


\section{Declarations}

Ethics approval and consent to participate Not applicable

Consent for publication Not applicable

Conflict of interest The authors declare no competing interests.

Open Access This article is licensed under a Creative Commons Attribution 4.0 International License, which permits use, sharing, adaptation, distribution and reproduction in any medium or format, as long as you give appropriate credit to the original author(s) and the source, provide a link to the Creative Commons licence, and indicate if changes were made. The images or other third party material in this article are included in the article's Creative Commons licence, unless indicated otherwise in a credit line to the material. If material is not included in the article's Creative Commons licence and your intended use is not permitted by statutory regulation or exceeds the permitted use, you will need to obtain permission directly from the copyright holder. To view a copy of this licence, visit http://creativecommons.org/licenses/by/4.0/.

\section{References}

Bumpus AG, Liverman DM (2008) Accumulation by decarbonization and the governance of carbon offsets. Econ Geogr 84(2):127-155

Davis TJ, Keller CP (1997) Modelling uncertainty in natural resource analysis using fuzzy sets and Monte Carlo simulation: slope stability prediction. Int J Geogr Inf Sci 11(5):409-434. https://doi.org/10.1080/ 136588197242239

Do H, Luedeling E, Whitney C (2020) Decision analysis of agroforestry options reveals adoption risks for resource-poor farmers. Agron Sustain Dev 40(3):103. https://doi.org/10.1007/s13593-020-00624-5

Entezari R, Brown PE, Rosenthal JS (2020) Bayesian spatial analysis of hardwood tree counts in forests via MCMC. Environmetrics 31(4) https://doi.org/10.1002/env.2608

FAO (2016) State of the World's Forests 2016: forests and agriculture: land-use challenges and opportunities. FAO, Rome

FAO (2018) The State of the World's Forests 2018 - Forest pathways to sustainable development. FAO, Rome. Licence: CC BYNC-SA 3.0 IGO.

FAO (2020) Forest land emissions and removals. Global, regional and country trends 1990-2020. FAOSTAT Analytical Brief Series No. 12. FAO, Rome

Favretto N, Luedeling E, Stringer LC, Dougill AJ (2017) Valuing ecosystem services in semi-arid rangelands through stochastic simulation. Land Degrad Dev 28(1):65-73

Feucht Y, Zander K (2018) Consumers' preferences for carbon labels and the underlying reasoning. A mixed methods approach in 6 European countries. J Clean Prod 178:740-748. https://doi.org/10.1016/j.jclep ro.2017.12.236

Fischer PW, Cullen AC, Ettl GJ (2017) The effect of forest management strategy on carbon storage and revenue in Western Washington: a probabilistic simulation of tradeoffs. Risk Anal 37(1):173-192. https:// doi.org/10.1111/risa.12611

Foster BC, Wang D, Auld G, Cuesta RMR (2017) Assessing audit impact and thoroughness of VCS forest carbon offset projects. Environ Sci Policy 78:121-141. https://doi.org/10.1016/j.envsci.2017.09.010

Fürstenau C, Badeck FW, Lasch P, Lexer MJ, Lindner M, Mohr P, Suckow F (2007) Multiple-use forest management in consideration of climate change and the interests of stakeholder groups. Eur J For Res 126(2):225-239

Galik CS, Jackson RB (2009) Risks to forest carbon offset projects in a changing climate. For Ecol Manag 257(11):2209-2216

The Gold Standard (2017) Afforestation/reforestation GHG emissions reduction \& sequestration methodology, Version 1. Geneva. The Gold Standard.

The Gold Standard (2018) Land-use \& forests activity requirements, Version 1.1. Geneva. The Gold Standard.

Hamrick K, Gallant M (2017) State of the voluntary carbon markets 2017: Unlocking potential. Washington. Forest Trends' Ecosystem Marketplace. 
Herr D, Blum J, Himes-Cornell A, Sutton-Grier A (2019) An analysis of the potential positive and negative livelihood impacts of coastal carbon offset projects. J Environ Manag 235:463-479. https://doi.org/10. 1016/j.jenvman.2019.01.067

Hubbard DW (2014) How to measure anything: finding the value of "intangibles" in business (3rd ed., Vol. 45). Hoboken. John Wiley \& Sons Inc. https://doi.org/10.5860/choice.45-6882

ICROA. (2014). Unlocking the hidden value of carbon offsetting. London. Imperial College London.

Kahneman, D. (2011). Thinking, fast and slow. London. Penguin Books

Kangas AS, Kangas J (2004) Probability, possibility and evidence: approaches to consider risk and uncertainty in forestry decision analysis. For Policy Econ 6(2):169-188

Kim H, House LA, Kim T-K (2016) Consumer perceptions of climate change and willingness to pay for mandatory implementation of low carbon labels: the case of South Korea. Int Food Agribus Manag Rev 19(4), 129-144 https://doi.org/10.22434/IFAMR2015.0095

Kollmuss A, Zink H, Polycarp C (2008) Making sense of the voluntary carbon market: a comparison of carbon offset standards. Stockholm Environment Institute and Tricorona. Stockholm.

Kumar M, Kalra N, Singh H, Sharma S, Singh Rawat P, Kumar Singh R, Kumar Gupta A, Kumar P, Ravindranath NH (2021) Indicator-based vulnerability assessment of forest ecosystem in the Indian Western Himalayas: an analytical hierarchy process integrated approach. Ecol Indic 125https://doi.org/10. 1016/j.ecolind.2021.107568

Lähtinen K, Haara A, Leskinen P, Toppinen A (2008) Assessing the relative importance of tangible and intangible resources: empirical results from the forest industry. For Sci 54(6):607-616

Lang S, Blum M, Leipold S (2018) What future for the voluntary carbon offset market after Paris? An explorative study based on the discursive agency approach. Clim Policy 19(4):414-426. https://doi. org/10.1080/14693062.2018.1556152

Lansing DM (2015) Carbon forestry and sociospatial difference: an examination of two carbon offset projects among indigenous smallholders in Costa Rica. Soc Nat Resour 28(6):593-608. https://doi.org/10. 1080/08941920.2014.948243

Lanzanova D, Whitney CW, Shepherd KD, Luedeling E (2019) Improving development efficiency through decision analysis: reservoir protection in Burkina Faso \}. Environ Model Softw 115:164-175

Lehmann I (2019) When cultural political economy meets 'charismatic carbon' marketing: a gender-sensitive view on the limitations of Gold Standard cookstove offset projects. Energy Res Soc Sci 55:146154. https://doi.org/10.1016/j.erss.2019.05.001

Liu L, Chen R, He F (2015) How to promote purchase of carbon offset products: labeling vs. calculation? J Bus Res 68(5):942-948 https://doi.org/10.1016/j.jbusres.2014.09.021

Lovell HC (2010) Governing the carbon offset market. WIREs Clim Change 1(3):353-362

Luedeling E, Gassner A (2012) Partial least squares regression for analyzing walnut phenology in California. Agric For Meteorol 158-159:43-52. https://doi.org/10.1016/j.agrformet.2011.10.020

Luedeling E, Goehring L, Schiffers K, Whitney C (2019) R Package 'decisionSupport' (Version 1.105.2) [Computer software].

Luedeling E, Oord AL, Malesu M, Shepherd KD, Ogalleh S, Kiteme B (2015) Fresh groundwater for Wajir - ex-ante assessment of uncertain benefits for multiple stakeholders in a water supply project in Northern Kenya . Front Environ Sci 3(March):1-18

Luedeling E, Shepherd KD (2016) Decision-focused agricultural research. Solutions J 7(October 2016):46-54

Lyon A, Wintle BC, Burgman M (2015) Collective wisdom: methods of confidence interval aggregation. J Bus Res 68(8):1759-1767

MacKerron GJ, Egerton C, Gaskell C, Parpia A, Mourato S (2009) Willingness to pay for carbon offset certification and co-benefits among (high-)flying young adults in the UK. Energy Policy 37(4):1372-1381

Manaye A, Tesfamariam B, Tesfaye M, Worku A, Gufi Y (2021) Tree diversity and carbon stocks in agroforestry systems in northern Ethiopia. Carbon Balance Manage 16:14. https://doi.org/10.1186/ s13021-021-00174-7

Mithofer D, Roshetko JM, Donovan JA, Nathalie NE, Robiglio V, Wau D, Sonwa DJ, Blare T (2017) Unpacking 'sustainable' cocoa: do sustainability standards, development projects and policies address producer concerns in Indonesia, Cameroon, and Peru? Int J Biodivers Sci Ecosyst Serv Manag 13(1):444-469

Querdenker GmbH (Ed.). (2017). FuturoVerde: Broschüre zum 10-jährigen Bestehen des Projektverbunds.

R Core Team (2018) R: A language and environment for statistical computing [Computer software]. (2018). R Foundation for Statistical Computing. Vienna, Austria. https://www.r-project.org/

Rock, H. (2016). Economic analysis of mixed forestry and agroforestry systems using a multi-period modeling approach (Masterthesis). Universität Hohenheim. 
Rauscher HM, Lloyd FT, Loftis DL, Twery MJ (2000) A practical decision-analysis process for forest ecosystem management. Comput Electron Agric 27(1-3):195-226

Shepherd K, Hubbard D, Fenton N, Claxton K, Luedeling E, De Leeuw J (2015) Development goals should enable decision-making. Nature 523:152-54

The Redd Desk. (2014). CarbonFix Standard (Gold Standard) I The REDD Desk. https://theredddesk.org/ encyclopaedia/carbonfix-standard-gold-standard

Rosenstock TS, Mpanda M, Rioux J, Aynekulu E, Kimaro AA, Neufeldt H, Shepherd KD, Luedeling E (2014) Targeting conservation agriculture in the context of livelihoods and landscapes. Agric Ecosyst Environ 187:47-51. https://doi.org/10.1016/j.agee.2013.11.011

Roshetko JM, Dawson IK, Urquiola J, Lasco RD, Leimona B, Weber JC, Bozzano M, Lillesø J-PB, Graudal L, Jamnadass R (2018) To what extent are genetic resources considered in environmental service provision? A case study based on trees and carbon sequestration. Clim Dev 10(8):755-768. https://doi. org/10.1080/17565529.2017.1334620

Sherman LA, Brye KR (2019) Soil chemical property changes in response to long-term pineapple cultivation in Costa Rica. Agrosyst Geosci Environ 2(1):1-9. https://doi.org/10.2134/age2019.07.0052

Sommer-Guist C, Assenmacher H (2015) ForestFinest: Das Magazin für weltweite Waldwir tschaft. https:// www.forestfinance.de/fileadmin/ForestFinanceContent/ForestFinest/ForestFinest_2-2015_screen.pdf

Thomas E, Jalonen R, Loo J, Boshier D, Gallo L, Cavers S, Bordács S, Smith P, Bozzano M (2014) Genetic considerations in ecosystem restoration using native tree species. For Ecol Manag 333:66-75. https:// doi.org/10.1016/j.foreco.2014.07.015

Tienhaara K (2012) The potential perils of forest carbon contracts for developing countries: cases from Africa. J Peasant Stud 39(2):551-572

UNFCCC (1997) Kyoto protocol to the United Nations framework convention on climate change. Kyoto. UN Treaty Database

UNFCCC (2007) The Kyoto protocol mechanisms. Bonn, Germany

Van der Gaast W, Sikkema R, Vohrer M (2018) The contribution of forest carbon credit projects to addressing the climate change challenge. Clim Policy 18(1):42-48. https://doi.org/10.1080/14693062.2016. 1242056

van der Werf GR, Morton DC, DeFries RS, Olivier JGJ, Kasibhatla PS, Jackson RB, Collatz GJ, Randerson JT (2009) CO2 emissions from forest loss. Nat Geosci 2(11):737-738. https://doi.org/10.1038/ngeo671

Vecchio R (2013) Determinants of willingness-to-pay for sustainable wine: evidence from experimental auctions. Wine Econ Policy 2(2):85-92. https://doi.org/10.1016/j.wep.2013.11.002

Vecchio R, Annunziata A (2015) Willingness-to-pay for sustainability-labelled chocolate: an experimental auction approach. J Clean Prod 86:335-342

Wafula J, Muchiri C, Shepherd KD, Tamba Y, Nyongesa J, Karimjee Y, Malava G, de Leeuw J, Luedeling E, Koech G (2018) Probabilistic assessment of investment options in honey value chains in Lamu County, Kenya. Front Appl Math Stat 4(March):1-11

Whitney CW, Lanzanova D, Muchiri C, Shepherd KD, Rosenstock TS, Krawinkel M, Tabuti JRS, Luedeling E (2018) Probabilistic decision tools for determining impacts of agricultural development policy on household nutrition. Earth's Futur 6(3):359-372

Whitney CW, Tabuti JRS, Hensel O, Yeh C-H, Gebauer J, Luedeling E (2017) Homegardens and the future of food and nutrition security in southwest Uganda. Agric Syst 154:133-144

Wold S (1995) Pls for multivariate linear modeling. In H. van de Waterbeemd (Ed.), Methods and principles in medicinal chemistry: v. 2. Chemometric methods in molecular design (195-2018). VCH https://doi. org/10.1002/9783527615452

The World Bank (2004) Sustaining forests: a development strategy. Appendix 2, p. A-3. Washington, DC.

Wright JA, DiNicola A, Gaitan E (2000) Latin American forest plantations: opportunities for carbon sequestration, economic development, and financial returns. J For 98(9):20-23. https://doi.org/10.1093/jof/ 98.9.20

Publisher's Note Springer Nature remains neutral with regard to jurisdictional claims in published maps and institutional affiliations. 